\title{
O tempo vivido pelo alfabetizando adulto nas aulas de matemática
}

\section{The time lived by the adult literacy student in mathematics classes}

\author{
Maria de Fátima Teixeira Barreto ${ }^{1}$
}

\begin{abstract}
RESUMO
As análises deste trabalho enfocam os modos pelos quais o alfabetizando adulto vive o seu tempo nas aulas de Matemática, possibilitando compreender como se presentifica, mediante a manifestação do seu modo de ser com o outro, no mundo, e com a Matemática. Permitem ainda, investigar como o alfabetizando adulto se abre às possibilidades em seu processo de inserção no mundo da leitura e escrita da Matemática. Enfim possibilitam falar de seu tempo vivido nesse processo.

Palavras-chave: tempo vivido; letramento em matemática; Alfabetização de adulto.
\end{abstract}

\begin{abstract}
The analyses of this paper focus on the ways by which the adult literacy student lives his time in mathematics classes, making it possible to understand how he presents himself by means of the manifestation of his way of being with the other, of being in the world, and of being with mathematics. They also permit us to investigate how the adult literacy student opens himself to the possibilities in his process of insertion into the world of reading and writing of mathematics. Finally they permit him to talk about his time lived in this process.

Keywords: lived time; literacy in mathematics; Adult literacy.
\end{abstract}

1. Dra ${ }^{a}$. em Ed. Matemática, Profa . adjunta na Fe-UFG-E-mail: fato823@terra.com.br. 


\section{Introdução}

Este trabalho compartilha compreensões obtidas com a pesquisa "O tempo vivido pelo alfabetizando adulto nas aulas de matemática". Por ela me propus a investigar o modo como o alfabetizando adulto vive o seu processo de alfabetização matemática em situações formais de escolarização. Foquei a experiência vivida pelo aluno em sala de aula no processo de investigação, por entender que esse poderia ser um veio para pesquisar o seu processo de construção do conhecimento matemático. Com essa compreensão, olhando para a sala de aula, inquiri sobre o modo pelo qual o aluno alfabetizando adulto se presentifica, mediante a manifestação do seu modo de ser com o outro, no mundo, e com a Matemática; indaguei sobre como esse aluno se abre às possibilidades, e como tudo isso interfere em seu processo de inserção no mundo da leitura e escrita da Matemática.

Tais questões se sustentam na compreensão de tempo como estrutura de possibilidades, ou seja, de tempo vivido. A ideia de tempo vivido (MINKOWSKI, 1982), revê a concepção de tempo da ciência, considerando o tempo não como sucessão de instantes, algo externo ao sujeito, mas algo inerente à sua existência, relacionado à experiência vivida. A essa concepção aproximei a ideia de ser (HEIDEGGER, 2000), entendida como pre-sença, caracterizado pelo modo de ser-no-mundo-com-o-outro. Assim, busquei compreender como se dá a experiência vivida no modo de o adulto se pre-sentar nas aulas de Matemática.

Ao falar de tempo vivido, falo de um tempo que não se faz sem o sendo do ser. Assim quando se dá tempo, se dá também o ser. Para Heidegger (1973), o dar no "dá-se ser" revela-se como destino da pre-sença ${ }^{2}$, que se faz no decurso de sua existência, mediante as escolhas efetuadas na temporalidade e historicidade próprias. Na pre-sença, conforme Heidegger (2000), o ser está aberto às possibilidades; é um ser de possibilidade que se projeta sendo-no e sendo-com o mundo e com as outras pre-senças. Sendo no mundo com o outro, a pre-sença é ser responsável, uma responsabilidade em relação a si mesmo e ao mundo. Nesse existir responsável, o ser é sempre posto em jogo, podendo realizar suas possibilidades no existir, pois, conforme vai sendo, escolhendo, renunciando, opinando, omitindo-se... vive a liberdade de superar-se e é capaz de transcender-se. Assim, pre-sença é sempre movimento, sempre um vir-a-ser que se dá no ciclo existencial em que se-é-sendo-no-mundo.

2. Traduzido do alemão Dasein, também encontrado como ser-aí. É a expressão utilizada por Heidegger para se referir ao Ser do ser que pergunta pelo ser. 
O tempo investigado se deu no contexto de uma sala de aula de Matemática do programa Aja-expansão, programa esse destinado à iniciação formal de analfabetos de Goiânia-GO ao mundo letrado. O alfabetizando adulto, sujeito desta investigação, possui idade superior a 55 anos, é pre-sença, com possibilidades de compreensão, interpretação, comunicação, análise e reflexão próprias, vivendo em um ambiente de letramento em Matemática. O termo letramento, conforme definido por Soares (1998), ao referir-se à língua materna, transposto para o contexto da linguagem matemática, refere-se ao estado ou condição que assume aquele que aprende a ler e escrever. Para a autora, "Implícita neste conceito está a idéia de que a escrita traz conseqüências sociais, culturais, políticas, econômicas, cognitivas, lingüísticas, quer para o grupo social em que seja introduzida, quer para o indivíduo que aprenda a usá-la" (SOARES, 1998, p. 17).

Nesta concepção, ao tornar-se letrado, a pessoa amplia suas possibilidades de, antecipando sua existência, tornar-se diferente, pois vai adquirindo um outro estado, mudando sua condição. Para a formação da pessoa letrada em matemática, à escola cabe favorecer a apropriação do significado dos entes matemáticos pela pre-sença, por intermédio da busca de relações e elaboração de articulações pertinentes a esse conhecimento.

Compreendo que a elaboração de significações para os entes matemáticos dá-se num ir e vir de situações em que se possa discutir o conhecimento e a linguagem que o expressa e estrutura, por isso, desenvolvi uma proposta de trabalho em que, a partir do número utilizado em contexto social, representando os processos de nomear, medir, ordenar, valorar (TEIXEIRA, 1998) e, atendendo à função social da linguagem - heurística, informacional, pessoal, imaginativa, internacional, regulatória, instrumental, imaginativa (HALLIDAY, 1983) - as alunas pudessem ir se conduzindo da linguagem cotidiana, predominantemente oral, à proposicional, com características de escrita, estruturante do conhecimento em questão. No acompanhamento de tal proposta, busquei elementos que me possibilitassem investigar o modo de pre-sença dos sujeitos, inserindo-se no universo da linguagem matemática escolarizada.

Para Bicudo (1996), a apropriação dos entes matemáticos, se dá envolto pela afetividade e a compreensão como modos de ser da pre-sença. Como ser de possibilidades que se projeta ao ser-no-mundo, na afetividade, a pre-sença pode distanciar-se ou aproximar-se, tendo aversão ou se disponibilizando para o trato com o ente matemático. Daí, a aula de Matemática abrange tanto a pre-sença do professor quanto dos alunos, que ao serem-uns-com-os-outros, são cuidado e escuta. Assim, conduzi as reflexões para o cuidado com a comunicação e a interpretação, de modo que a compreensão primeira dos alunos pudesse ser refinada em pensamento esclarecedor e, se possível, expressa em linguagem proposicional. 
Enfim, por intermédio do encaminhamento pedagógico a que me propus desenvolver, intentei investigar "como o alfabetizando vive a sua temporalidade em sala de aula, sendo-com-o-outro", desenvolvendo suas tarefas; "como e o que sentem" em sua vivência como alfabetizando; como vivem as mudanças como seres de possibilidades, como pre-sença.

\section{A pesquisa}

Para o desenvolvimento da investigação proposta, fiz opção pela pesquisa qualitativa numa abordagem fenomenológica conforme Martins e Bicudo (1989). Seguindo o itinerário proposto por essa abordagem, procedi à descrição da manifestação do fenômeno situado (BICUDO, 2000). Nesta pesquisa, as descrições se referem às transcrições das fitas das aulas e das entrevistas realizadas com os sujeitos no início do período de aulas.

No estudo das entrevistas, busquei compreender como os sujeitos se percebiam com relação à leitura e à escrita, uma vez que, para eles, o domínio desses recursos significava um pro-jeto. Procurei entender que futuro eles estariam tentando antecipar e o que esperavam viver na escola, na sua relação com o mundo e com o outro; como se percebiam relativamente ao conhecimento matemático e como a Matemática estaria presente no processo de antecipação do futuro. No estudo das aulas voltei-me para o cotidiano da sala de aula, na tentativa de compreender como se manifestam os sujeitos envolvidos no processo de inserção no universo da linguagem matemática.

Para encaminhamento do trabalho realizei a transcrição integral das entrevistas e aulas e, procedi à sua leitura, repetidas vezes, buscando, passagens significativas do ponto de vista da pergunta orientadora.

A partir das passagens significativas destacadas, continuei a análise, realizando sucessivas reduções, buscando elementos convergentes que pudessem reunir as asserções. Construí, assim, a tabela de convergências menores, sendo 24 a partir das entrevistas e 21 das aulas, que depois foram agrupadas compondo o quadro de convergências maiores como segue: 


\begin{tabular}{|c|c|}
\hline CONVERGÊNCIAS MENORES & $\begin{array}{l}\text { CONVERGÊN- } \\
\text { CIAS MAIORES } \\
\text { ANTEVISTAS }\end{array}$ \\
\hline $\begin{array}{l}\text { 1 - A leitura se apresenta como um sonho. } \\
\text { 2 - A escrita do nome é a motivação para ir à escola. } \\
4 \text { - Diversão, distração e convívio social são motivações para ir } \\
\text { à escola. } \\
5 \text { - A leitura e a escrita são caminhos para a independência. } \\
12 \text { - A escritura de cartas é motivação para aprender a escrever. } \\
13 \text { - A leitura é considerada porta para o conhecimento do } \\
\text { mundo e de tudo. } \\
14 \text { - O conhecimento escolar pode modificar o modo de tratar } \\
\text { os outros, de conversar. } \\
17 \text { - A aprendizagem da leitura lhe servirá para auxiliar os } \\
\text { outros na compreensão do texto bíblico. } \\
22 \text { - A leitura e a escrita podem contribuir para uma mudança } \\
\text { na qualidade de vida. } \\
23 \text { - O desejo de aprender a fazer contas é o que a motiva a ir } \\
\text { para a escola. } \\
24 \text { - O desenvolvimento do gosto pela leitura é um desejo, } \\
\text { embora ache que não vai conseguir porque isto é um dom. }\end{array}$ & $\begin{array}{l}\text { Expectativas em } \\
\text { relação à apren- } \\
\text { dizagem e ao } \\
\text { ambiente escolar }\end{array}$ \\
\hline $\begin{array}{l}3 \text { - Desesperança ao não se ver capaz de aprender a ler. } \\
6 \text { - O domínio da escrita do nome é ainda uma dificuldade. } \\
7 \text { - Dificuldade na formação de palavras utilizando as letras já } \\
\text { conhecidas. } \\
8 \text { - Revolta e nervosismo por sentir-se incapaz de aprender. } \\
9 \text { - Vergonha por não saber ler. } \\
16 \text { - Desconhecimento das regras da escrita: desejo de aprender. } \\
20 \text { - Domínio da leitura e escrita dos números e não-domínio } \\
\text { do registro das operações, limitando-se ao cálculo mental. }\end{array}$ & $\begin{array}{l}\text { Percepção de si } \\
\text { mesma }\end{array}$ \\
\hline $\begin{array}{l}10 \text { - A Matemática não é vista como necessária. } \\
18 \text { - Compreensão da Matemática como um instrumento para } \\
\text { não ser enganada. }\end{array}$ & $\begin{array}{l}\text { Compreen- } \\
\text { são acerca do } \\
\text { conhecimento } \\
\text { matemático }\end{array}$ \\
\hline
\end{tabular}


11 - A falta de compromisso com a escola foi responsável pela não-aprendizagem.

15 - As atribuições domésticas e as preocupações financeiras atrapalham a aprendizagem e impedem a assiduidade às aulas. 19 - A dificuldade de memorização atrapalha seu desempenho

Obstáculos para a aprendizagem escolar.

21 - Falta de oportunidade: nunca estudou ou estudou pouco.

QUADRO 1 - CONVERGÊNCIAS ELABORADAS COM BASE NO ESTUDO DAS ENTREVISTAS

\begin{tabular}{|c|c|}
\hline CONVERGÊNCIAS MENORES & $\begin{array}{l}\text { CONVERGÊN- } \\
\text { CIAS MAIORES }\end{array}$ \\
\hline $\begin{array}{c}1 \text { - Silêncio e modos de ausentar-se - manifestação de } \\
\text { incompreensão. } \\
2 \text { - Disponibilidade para participar da aula: acompanhando, } \\
\text { participando, envolvendo-se, manifestando desejo de aprender, } \\
\text { descobrindo, fazendo junto, acompanhando o grupo. } \\
5 \text { - Avaliação da atuação da professora e da condução da aula } \\
\text { pelas alunas. Manifestação de humor com relação à atividade. } \\
7 \text { - Manifestações em relação ao uso do material didático. } \\
9 \text { - Reafirmação de seu jeito de agir, desejo de ser ouvida. } \\
11 \text { - Tratamento maternal; cuidado com o outro e com a } \\
\text { professora. } \\
13 \text { - Explicitação de pré-concepções acerca da Matemática e } \\
\text { da aprendizagem: rejeição, resistência, impaciência, satisfação, } \\
\text { insatisfação. } \\
14 \text { - Desejo, necessidade de orientação individualizada. } \\
19 \text { - Tentativa de resposta sem compreensão. }\end{array}$ & $\begin{array}{l}\text { Modos de pre- } \\
\text { sença do aluno }\end{array}$ \\
\hline $\begin{array}{l}6 \text { - Exposição de conteúdo; explicitação de regras; respostas às } \\
\text { próprias perguntas. } \\
18 \text { - Incentivo à frequência escolar; explicitação da proposta. }\end{array}$ & $\begin{array}{l}\text { Modos de pre- } \\
\text { sença } \\
\text { da professora }\end{array}$ \\
\hline
\end{tabular}




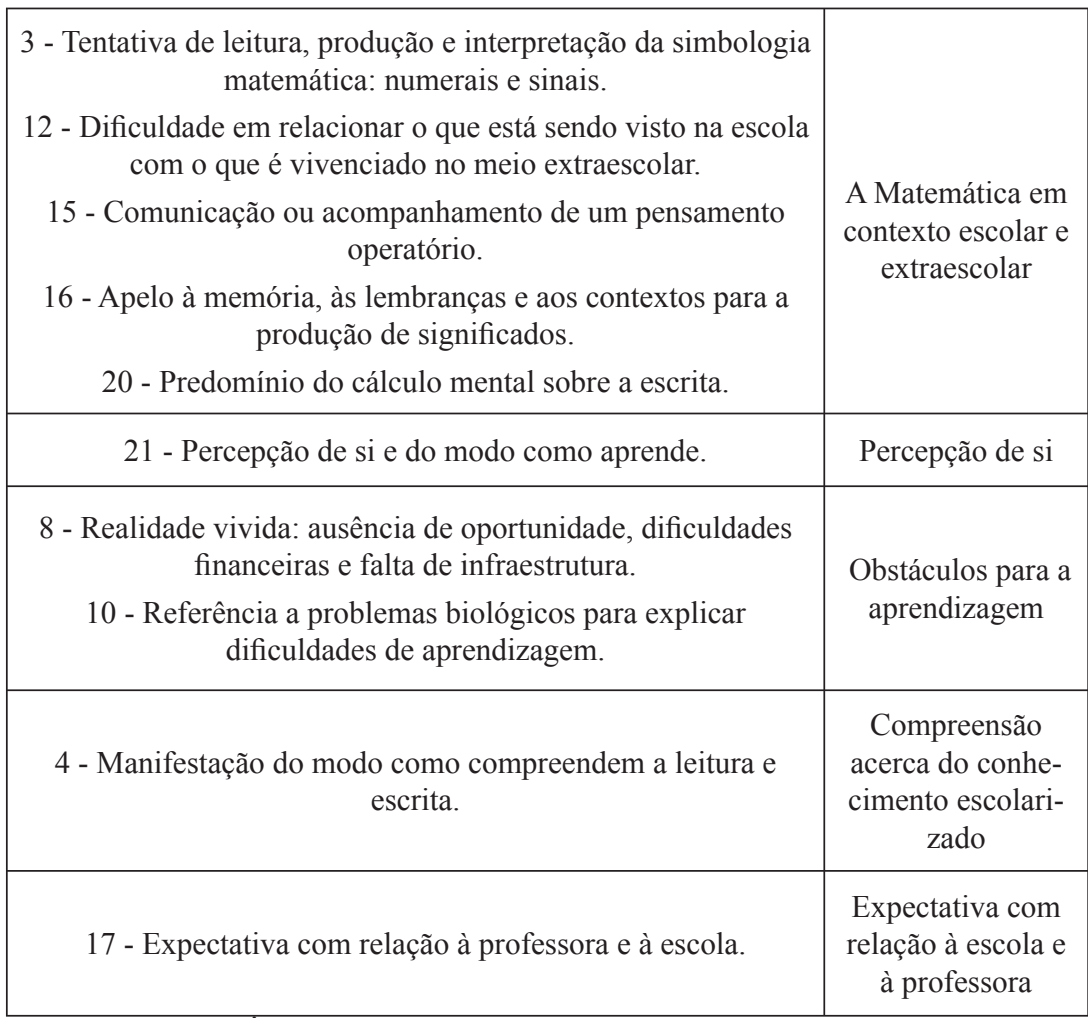

QUADRO 2 - CONVERGÊNCIAS ELABORADAS COM BASE NO ESTUDO DAS AULAS

O encaminhamento metodológico seguido apontou-me as categorias abertas que doravante estarei explicitando: a escola e a alfabetização de adultos; modos de pre-sença dos sujeitos nas aulas de matemática. As categorias são fruto da trajetória de investigação, oriundas das sucessivas reduções realizadas pelo pesquisador. As experiências prévias do pesquisador, embora não devam conduzir a elaboração das categorias, compõem o campo de percepção constituído pela co-percepção, co-participação de outros sujeitos que, por viverem experiências comuns, "[...] permitem o compartilhar compreensões, comunicações, desvendar discursos, estabelecendo-se a esfera da intersubjetividade" (BICUDO, 1994, p. 19). 


\section{A escola e a alfabetização de adultos}

A interpretação das compreensões elaboradas me levou a pensar a escola como ambiente para a ampliação de possibilidades e antecipação do vir-a-ser; a refletir acerca da compreensão dos sujeitos em situações escolares de inserção no universo da linguagem matemática e a apontar a pre-sença como modo de ruptura com a mesmice aparente em sala de aula.

Entendo que há um movimento no tempo vivido pela pre-sença no ciclo existencial em que se-é-sendo-no-mundo. E que, nesse movimento, a pre-sença é um Ser de possibilidades que se projeta sendo-no e sendo-com o mundo e com as outras pre-senças, sempre de modo responsável por si mesmo, projetando-se em escolhas, superando-se, transcendendo-se.

Os sujeitos dessa investigação, como pre-sença, estavam em um ambiente escolarizado com a finalidade de antecipar seu futuro e projetar-se. Pensar a escola como ambiente para a ampliação de possibilidades e antecipação do vir-a-ser.

Em sentido contrário, algumas consideram que alfabetizar-se é abrir portas para saber tudo, para dominar a gramática da língua escrita, dominar a escrita do nome, deleitar-se com a leitura prazerosa e até para melhorar as condições materiais de existência. Tais concepções resultam em abertura para a aprendizagem da leitura e da escrita, mas não são atribuídas ao conhecimento matemático. Da maneira como a alfabetização é divulgada, o conhecimento da linguagem matemática e outras formas de linguagem não são percebidos como constitutivas do processo de alfabetização. $\mathrm{O}$ conhecimento é trabalhado pela escola de modo compartimentado, criando uma falsa ideia de que o domínio da leitura e da escrita de letras e palavras é suficiente para que alguém seja considerado alfabetizado.

O discurso das alunas revela que não viam como necessário o conhecimento da linguagem matemática. Isso porque chegaram à idade adulta sem saber escrever o pensamento matemático realizado para a solução de problemas diários e, dificilmente, serão solicitadas a apresentá-lo ou a lidarem com a matemática existente por intermédio da sua escrita. Quando surge alguma necessidade imediata em relação ao domínio da leitura de alguma simbologia matemática, recorrem aos outros, solicitando orientações orais e se dão por satisfeitas. Sua percepção de mundo e de si mesmas encontra-se em conformidade com as compreensões elaboradas ao ser-no-mundo-com-os-outros e com suas condições de existência que, por sua vez, resultam em modos de compreensão, formando um círculo vicioso. 
Um dos papéis da escola é ampliar modos de percepção do mundo circundante, apontando o conhecimento como forma de ampliação de possibilidades de ser e de existir nesse mundo, o que pode resultar em outros modos de compreender. A escola, no entanto, tanto pode contribuir para a dissolução do modo da pre-sença no todos nós... ninguém (HEIDEGGER, 2000) quanto para tornar as possibilidades transparentes para os próprios alunos, libertando-os para vivê-las.

Para além das pressões externas ou da vida social como manutenção ou progressão no emprego, ou ingresso no mercado de trabalho, as depoentes nos revelam que buscam a escola na esperança de que o processo educativo lhes confira novas perspectivas de autorrespeito, autoestima e autonomia, como consequência das habilidades de ler e escrever. Para atender a esses sujeitos, a alfabetização deveria englobar o contato com a diversidade de linguagens existentes na sociedade, inclusive a escrita, com o fim de possibilitar a abertura para conhecer e intervir no mundo no qual se é. Assim, ampliar-se-iam as expectativas das alunas com relação à escola, à leitura e à vida.

O principal interesse de algumas alunas, ao buscarem a escola, é estarcom-o-outro: "Eu gosto de aprender pra tá aqui com vocês". Nesse estar com o outro percebo a possibilidade de melhorar suas condições de existir, pois estarcom-o-outro na escola significa abertura para a ampliação das possibilidades de lazer e de conhecer o mundo no qual se é. Esse conhecimento pode contribuir para a socialização do saber letrado, tomado como um trampolim para outros conhecimentos, dada a abertura de possibilidades de aprendizagens que cria. Mas tal socialização deve visar à criação de situações em que os alunos elaborem interpretações de sua compreensão de si e do mundo.

As novas mídias possibilitam a compreensão do mundo circundante e favorecem o convívio com a diversidade cultural e com as diferentes formas de manifestação e registro da nossa cultura, por isso devem ser inseridas também nas atividades desenvolvidas.

Compreendo, entretanto, que o acesso à leitura e à escrita, ou à diversidade cultural existente no mundo não garante, por si só, novos modos de atuação ou a mudança de condição de existência. Os modos como o indivíduo se relaciona com a informação, como se põe em atividade e como se presentifica, junto com a possibilidade de acesso ao conhecimento, podem resultar em maneiras diferentes de pensar, de desenvolver-se cognitivamente, que estabelecem condições de existir na facticidade do ser.

Como na relação entre escola e aluno com a idade em que estão às alunas partícipes dessa pesquisa não há as pressões sociais do mercado de trabalho, como ocorre com o adulto mais jovem, é possível a criação de uma escola voltada para a compreensão das possibilidades da pre-sença, até mesmo do processo 
de envelhecimento. Mais que se preocupar com promoção de série, com grade curricular, a escola pode compartilhar leituras e discussões sobre a própria vida, sobre as possibilidades de realização de ordem pessoal dos envolvidos. Desse modo, pode tanto atender à expectativa de que contribua para as mudanças de condições de existência e de autoestima quanto apontar outros modos de viver e de envelhecer.

As mudanças estão relacionadas com a maneira como cada um vive o seu tempo: em atividade, em espera, em esperança, no desejo, em ato ético, em prece. E nesse modo de antecipar o futuro, a instituição escola pode contribuir tanto para libertação quanto para a conformação do indivíduo ao atendimento das demandas sociais, mantendo-o no todos nós... ninguém a que se refere Heidegger. O letramento, tão enfatizado pelos programas de alfabetização atuais faz referência às mudanças de condição ou estado. No entanto, essas só podem ocorrer se, pelo domínio das habilidades de ler e escrever e não somente pela escrita da palavra, a pessoa puder se perceber sendo-no-mundo-com-os-outros, ampliando e criando possibilidades de existir, antecipando o futuro e se vendo em movimento para se projetar.

\section{Modos de pre-sença dos sujeitos nas aulas de Matemática}

Esta categoria explora os modos de pre-sença dos sujeitos investigados, projetando-se, ampliando possibilidades e realizando escolhas na vivência de situações de sala de aula ao se envolverem com a linguagem e os pensamentos matemáticos.

Para a discussão desta categoria, trago a ideia de disposição e compreensão, existenciais $^{3}$ da pre-sença, apontadas por Heidegger (2000) como possibilitadoras do lançar-se a destinações. A disposição, conforme o autor é mais que um estado psicológico. Ela possibilita à pre-sença abrir-se ou esquivar-se em seu estar-lançado. São modos de disposição tanto o humor quanto o temor. E aqui o humor inclui todas as suas variações ao revelar como alguém está e em que se torna na falta de humor a pre-sença se torna enfadonha a si mesma; no mau humor a pre-sença se torna um peso para si mesma. Neste último estado, a disposição é pouco considerada na reflexão, o que faz com que a pre-sença se precipite para o mundo, cegando-se ou não se permitindo ver.

Do mesmo modo que o humor, o temor, como modo de disposição, apresen-

3. Termo utilizado por Heidegger (2000, p. 39) para designar uma determinação constitutiva da existência, sendo-lhe essencial, fundante. 
ta variações. São formas de temor: pavor, horror, terror, timidez, acanhamento, receio e estupor. Teme-se algo ou por algo e este temor também possibilita a abertura. "A pre-sença como ser no mundo é 'temerosa'. Ser temerosa é uma possibilidade existencial" (HEIDEGGER, 2000, p. 196).

Para Heidegger, ao ser-no-mundo a pre-sença sempre está envolta em algum tipo de humor ou temor. Este estado conduz a pre-sença ao seu pré, visto que é por ele que se dá a abertura da pre-sença em seu estar lançado na facticidade de seu modo de existir. "A expressão estar-lançado deve indicar a facticidade de ser entregue à responsabilidade" (HEIDEGGER, 2000, p. 189).

Quando Heidegger fala de compreensão, não está se referindo a uma elaboração proposicional sobre o pensável. Para ele, "Toda visão pré-predicativa do que está à mão já é em si mesma uma compreensão e interpretação" (HEIDEGGER, 2000, p. 205).

O modo como alguém está e em que se torna presentifica-se no modo como compreende e interpreta o mundo circundante. O senso comum revela uma tendência em relacionarmos a aprendizagem com experiências de bemestar e as dificuldades de aprendizagem com o mal-estar. No entanto, Heidegger (2000) e Bornheim (1976) apontam experiências negativas agindo com função libertadora na existencialidade do ser. Uma das experiências negativas apontadas por ambos é a angústia. Com base nos estudos desses autores, entendo que o ato de pensar envolve uma experiência negativa da angústia que impulsiona aquele que se predispõe a praticá-lo para a busca da superação da negatividade, levando-o a assumir-se e a transcender-se. $\mathrm{O}$ sentimento da experiência negativa é um estado de afecção; portanto, é um modo de disposição.

Enfim, entendendo a disposição e a compreensão como aberturas para o conhecimento existencial, compreendo que ao ser no mundo, o homem já se encontra sendo disposição e compreensão. Assim sendo, vai realizando o conhecimento de si mesmo e do mundo, o qual, se desdobrado em interpretações e expressões, caminha em direção da construção do conhecimento predicativo.

Por ser tanto intelectual quanto existencial, a compreensão acontece desde o momento em que a pre-sença, lançada à destinação, se põe em situação de antecipação do seu futuro, seja em atividade, desejo, espera, esperança ou ato ético (BICUDO, 2003). A pre-sença, ao ser-no-mundo-com-o-outro sempre compreende o mundo circundante e a si própria de algum modo. Na interpretação, tal compreensão se corporifica sendo, de início, pré-predicativa, mas, após desdobramentos de atos cognitivos, pode ascender a um nível mais elaborado, o predicativo.

Em relação à concepção sobre a Matemática, algumas expressões denunciam o desamparo a que se referiu Chamie (1990). O desamparo não é uma 
experiência negativa que leva à transcendência, pelo contrário, ao tomar a Matemática como algo que não lhe é possível, as atitudes diante das aulas são de descrédito em relação a si mesmo e à condução das aulas. É o que se pode perceber nos depoimentos de JAC que se expressa de forma negativa em relação à Matemática, numa atitude que manifesta mau humor e repulsa. No mau humor a pre-sença se torna um peso e a disposição é pouco trabalhada na reflexão, tornando a pre-sença cega em relação a si mesma. São várias as situações em que a aluna se fecha para a ampliação de suas compreensões:

- Não assume seus erros e dificuldades:

$$
\text { JAC - Então eu fiz errado, cê fez eu desmanchar. (sit 16) }
$$

- Acha enfadonha a tarefa de escrever o que está sendo discutido:

$$
J A C \text { - Tem que escrever isso tudo? (sit 17) }
$$

- Afirma não querer se envolver nas aulas destinadas ao estudo do número por já dominar esse conteúdo.

\section{$J A C$ - Não quero mexer com esses trem não. (sit 82)}

A aluna JAC, em várias outras situações expressa sua indisposição e resistência às atividades propostas, mostra não ter consciência da própria ignorância. Como não se põe em situação de enfrentamento, não há o que transcender. Não toma atitudes no sentido de vencer barreiras. Não se permite ter dúvida para, a partir de um ato de vontade, pôr em suspensão o que se propõe a conhecer, ou melhor, parece não se propor a conhecer algo quando se trata de Matemática. Pensa que já tem conhecimento suficiente. Em razão do mau humor vivido pela aluna, a pre-sença se fecha para a reflexão, não havendo, assim, a possibilidade do distanciamento entre o conhecedor e o conhecível. Não há uma tomada de consciência do ser pelo ser, nem a sua ascensão para um comportamento crítico e para a compreensão da necessidade de assumir a realidade pela qual se vê responsável, aliás, não se vê responsável pela realidade vivida.

Por trás das atitudes dessa aluna, há a crença de que aquilo que sabe é suficiente para ela e o desconhecimento da dimensão do conhecimento matemático e das possibilidades que esse conhecimento pode abrir. As crenças interferem em seu modo de conhecer, na abertura para o conhecimento e se concretizam em atitudes e comportamentos negativos.

Disposição diferente é apresentada por outras alunas e pela própria JAC em alguns momentos. As alunas percebem a importância da compreensão da linguagem matemática no dia-a-dia e se predispõem a aprender, ou melhor, desejam aprender a matemática escolar. No período em que participaram das aulas, as alunas viveram alguns momentos em que a negatividade da experiência lhes 
permitia projetar-se em compreensões. Experiências como a dúvida, a angústia e a insatisfação com o próprio saber implicam consciência da ignorância.

As alunas viveram também experiências positivas ao se sentirem satisfeitas com o resultado de sua ação e ao perceberem o próprio crescimento, o que resultou em melhoria da autoestima. Foram várias as situações em que o humor resultou em abertura para a aprendizagem. Viveram situações em que encaminham seu trabalho sem ajuda e se adiantam em relação ao grupo; expressam satisfação, se mostram seguras e demonstram resultado de aprendizagem. Manipulam sem dificuldade a calculadora; apresentam dúvidas surgidas da experiência. Em vários momentos as alunas manifestam interesse e demonstram estar envolvidas, acompanhando a aula.

$\mathrm{Na}$ abertura do estar-lançado, quando concebem interpretações para as compreensões obtidas, chegam à generalização, realizam interpretações e elaboram possibilidades projetadas na compreensão obtida, mesmo que de modo pré-reflexivo. Tais elaborações se dão em meio a perplexidades, confusões, bloqueios. Todos esses sentimentos surgem como resposta às experiências vividas no processo de aprender. Conduzir o trabalho apresentando caminhos para a discussão do pensamento operatório, antecipar a condução da aula, encaminhar sozinha seu trabalho e participar expressando conhecimento resultante das reflexões vividas em sala de aula, são atitudes que expressam a reelaboração da compreensão pelas alunas.

O que elas elaboram no pensamento operatório é o que lhes foi aberto em nível de elaboração pré-predicativa, fundada na percepção prévia, sintonizada com o humor no qual as situações vividas agiram, afetando-as. São situações em que ocorrem as experiências extraescolares de contato com o mundo circundante em termos do "para que serve", "da utilidade de algo para algo". As situações de sala de aula devem promover momentos de reflexão para que possam ascender a um nível mais elaborado de interpretação, ampliando a compreensão obtida.

A percepção de si mesmas, suas crenças com relação à Matemática e ao modo como se aprende se estão presentes em cada situação vivida e, também, na forma de lidarem com os recursos didáticos levados para a aula. Desconfiam da própria capacidade de agir, temem estragar o material, demonstram ter dificuldade em manipular os objetos de uso social como balança, calculadora, fita métrica, encartes de propaganda de lojas, numa completa estranheza. Ao desconfiarem da própria capacidade, sentem a limitação do seu conhecimento. Revela-se aqui o conflito entre o não saber e o medo de não conseguir aprender. Demonstram vergonha, impaciência e nervosismo ante as próprias limitações. Expressam sentimentos diversos como o desejo de se manter distante e o sentimento de inferioridade quando se comparam com outras alunas. As alunas manifestam ansiedade ante o fato de a aprendizagem não ser imediata e insatisfação com o 
ritmo no qual aprendem e com o esquecimento; não veem na desorientação um momento da aprendizagem que pode ser superado:

LID - Não, mais eu fico até cum vergonha docê. Ensina, ensina, ensina e a gente num sabe nada.

A superação dessa experiência negativa pode vir pela reflexão e pela interpretação da compreensão que se tem no pré-predicativo. Entendo ser nessa reflexão que a expressão da interpretação do compreendido pela oralidade pode ser explorado em sala de aula. No entanto, o que é expresso pela oralidade não é entendido pelas alunas como conhecimento, visto que prestigiam a escrita. Algumas alunas questionam o conhecimento de outras ao percebê-las acompanhando as reflexões na oralidade e desejam ver o conhecimento do grupo sendo colocado em prova na relação com a escrita.

As alunas expressam suas ansiedades e o medo de não alcançarem os objetivos pretendidos: aprender a ler e a escrever. Tais sentimentos resultam em expectativas, tanto para com as aulas, quanto também com relação à atitude da professora. Muitas vezes esperam mais pulso e firmeza de quem ensina.

A experiência negativa da ansiedade, da consciência, da ignorância, pode possibilitar a separação, o distanciamento necessário para que na reflexão o sujeito caminhe no sentido de compreender e interpretar o compreendido, elaborando uma linguagem proposicional rumo ao conhecimento científico. Da interpretação das compreensões elaboradas podem desencadear modos próprios de ser-com-o-outro-no-mundo em que o Ser se desvencilha da mesmice e nivelamento aparentes e não se perde no todos nós... ninguém. Amplia possibilidades de existir e projeta-se, antecipando futuros mediante a atividade, a prece, $\mathrm{o}$ ato ético, a esperança, o desejo, a espera (BICUDO, 2003) e tudo mais em que pode estar envolvido na sua temporalização.

$\mathrm{O}$ fato de que muitas vezes desconfiavam do que sabiam e estavam conscientes do que não sabiam resultou em atitudes dirigidas para vencer as barreiras, para buscar a transcendência. Outras vezes, envolvidas em um desamparo premente, viveram sufocadas pela baixa-estima e pelo desespero, distanciando-se de sua possibilidade de ruptura com as dificuldades, deixando-se cair no nivelamento de um todos nós inseguro e com aversão pelo conhecimento matemático.

A experiência negativa da ansiedade e da consciência da ignorância, em alguns momentos, possibilitou a vivência positiva da separação, do distancia- 
mento necessário para que, na reflexão, os sujeitos caminhassem no sentido de compreender e interpretar o compreendido, elaborado por seu modo de linguagem, e seguissem em direção ao conhecimento mais próximo do proposto pela Matemática escolarizada.

\section{Reflexões Finais}

Nesta investigação, inquiri sobre "como se dá o tempo vivido pelo alfabetizando adulto nas aulas de Matemática". As categorias por mim construídas, ao realizar esta investigação, falaram das expectativas dos sujeitos em relação ao ambiente escolar e à aprendizagem; da percepção que tinham sobre o que sabiam; de como se percebiam no processo de aprender; e, os empecilhos e dificuldades vividas para terem acesso à escola e nela permanecerem.

$\mathrm{O}$ estudo dos dados conduziu-me à reflexão sobre até que ponto a escola planejada para atender a clientela adulta tem respondido aos anseios e pro-jetos dos sujeitos envolvidos. E, explicitou humores e disposições dos sujeitos quando lidam com a Matemática em sala de aula.

As reflexões elaboradas apontam para a necessidade de um projeto de escola atento para a ampliação de possibilidades de existir e antecipar possibilidades de vir-a-ser dos envolvidos. Um ambiente para reflexão acerca dos modos de pré-sença e de rupturas com a mesmice aparente, que se dá não somente em sala de aula, mas nos diversos ambientes sociais. O conhecimento por ela veiculado contribui para essa reflexão, na medida em que for entendido como um modo de compreensão do mundo, que modifica modos de percepção, ampliando as possibilidades de ser e de existir, o que pode resultar em outros modos de compreender.

As situações vividas em sala de aula, nessa pesquisa, revelaram momentos em que a pre-sença, lançada à destinação da aprendizagem matemática, expressou modos de disposição e de compreensão. As alunas trouxeram para a facticidade existencial da sala de aula suas crenças e concepções sobre a Matemática, sobre como se aprende e sobre elas mesmas. Esse é um modo de viver o passado no pre-sente, antecipando o futuro. É tempo vivido.

Estar na sala de aula arriscando interpretações possibilitou-lhes viver o presente projetando o futuro. A antecipação e a projeção ocorreram em atividade, em espera, em desejo, em esperança, em prece, em ato ético.

Em atividade, expandiam o espaço, ao se realizarem em escolha pelo conhecer o que lhes parece difícil, que é algo que perdura. Em espera, mantinham 
a expectativa de que algo fosse feito para a sua aprendizagem, aguardavam que fosse dada a orientação passo a passo, a confirmação de suas ações e a interpretação de compreensões.

Pelo desejo e em esperança da aprendizagem da leitura e da escrita eram conduzidas à atividade com o fim de superar as dificuldades percebidas pela consciência da ignorância. O desejo impelia-as a alcançar além do que tinham à mão e ver além do que se percebiam podendo e sendo, impulsionando-as para ações a serem executadas individualmente. $O$ desejo vai além da atividade, pois, ao perdurar após a sua conclusão, resulta em mais outras atividades.

A esperança da aprendizagem esteve, algumas vezes, envolta em ansiedades, receios e até desesperança; outras vezes, realizou-se de modo tranquilo, sem a pressa característica da juventude. Puderam, então, deixar correr o fluxo da vida, sorvendo cada momento como único, como último, mas com entusiasmo e vibração movidas pelo desejo de mudança de seu estado e de sua condição.

Diante das dificuldades pediam a Deus a luz da abertura para o conhecimento, para a superação das dificuldades de aprendizagem atribuídas à velhice, das dificuldades financeiras e das dificuldades pessoais. Em ato ético sentiam-se responsáveis pelo devir.

Assim, as alunas, sujeitos desta pesquisa, viveram o seu tempo em sala de aula.

\section{REFERÊNCIAS}

BICUDO, M. A.V. Alfabetização: significados possíveis. In: MICOTTI, M. C. O. (Org.). Alfabetização: aspectos teóricos e práticos. Rio Claro (SP): Instituto de Biociências, 1999a. p. 29-40.

. Possibilidades de trabalhar a Educação Matemática na ótica da concepção heideggeriana de conhecimento. In: Quadrante, Lisboa, v. 5, n. 1, p. 5-27, 1996.

. Sobre a Fenomenologia. In: BICUDO, M. A.V.; ESPÓSITO, V. H. C. (Orgs.).

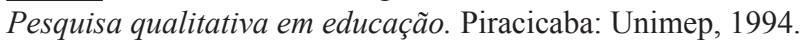

Humus).

Tempo, tempo vivido e história. Bauru: Edusc, 2003. 98 p. (Coleção

BORNHEIM, G. A. Introdução ao Filosofar: o pensamento filosófico em bases existenciais. 3. ed. Porto Alegre: Globo, 1976. 
CHÁCON, I. M. G. Matemática emocional: os afetos na aprendizagem matemática. Tradução de: Daisy Vaz de Moraes. Porto Alegre: Artmed, 2003.

CHAMIE, L. M. S. A relação aluno-matemática: alguns dos seus significados. Dissertação (Mestrado) - Unesp, Rio Claro, 1990.

FONSECA, M. C. F. R. Educação Matemática de Jovens e Adultos. Belo Horizonte: Autêntica, 2002.

HADDAD S.; PIERRO, M. C. Satisfação das necessidades básicas de aprendizagem de jovens e adultos no Brasil: contribuições para uma avaliação da década da Educação para Todos. In: SEMINÁRIO NACIONAL SOBRE EDUCAÇÃO PARA TODOS: IMPLEMENTAÇÃO DE COMPROMISSOS DE JONTIEM NO BRASIL, 1., 1999, Brasília (DF) Trabalhos apresentados... Brasília: INEP/MEC, 1999.

HALLIDAY, M. A. K. Language as social semiotic. 8. imp. Athenaeum, 1993. 254 p.

HEIDEGGER, M. Ser e tempo. Tradução de: Márcia de Sá Cavalcante. Petrópolis: Vozes, 2000. 325 p. (Parte I).

MINKOVSKI, E. El Tiempo Vivido. México: Fondo de Cultura Económica: 1982. SECRETARIA MUNICIPAL DE ENSINO DE GOIÂNIA. Projeto Aja-Expansão. Prioridade de Governo gestão 2001/2004, 46 p.

SOARES, M. Alfabetização e Letramento. São Paulo: Contexto, 2003. 123 p.

TEIXEIRA, M. F. Matemática e Língua Materna: por uma necessidade de aproximação em contexto escolar. Dissertação (Mestrado) - Unesp, Rio Claro, 1998. 